\title{
Monitoring applications for safe mining practices: case studies of sub-bench scale failures in hard rock and coal open cut mines
}

\author{
S Gale Thiess, Australia \\ L Farrington Thiess, Australia \\ P Bergström Boliden, Finland \\ M Suikkanen YARA, Finland \\ N Boldrini IDS GeoRadar, Italy \\ M Rubino IDS GeoRadar, Italy \\ N Coli IDS GeoRadar, Italy
}

S Naude IDS Georadar, Australia

CJ Stopka IDS GeoRadar, USA

C Preston IDS GeoRadar, USA

\begin{abstract}
In the modern mining industry, mining companies are coming under increasing pressure to improve the performance and efficiency of their operations. Special attention has been given not only to potential largescale movements, but also to local-scale instabilities within active mining areas which can be difficult to manage. Sub-bench scale failures pose a threat to miners and machinery due to the closeness to working areas and identifying these areas before failure helps minimise production interruption. For this reason, a comprehensive slope monitoring program should be introduced and required in every geotechnical risk assessment plan. This paper presents three case studies, an apatite mine and a nickel-PGE-copper mine located in Finland and an open cut coal mine situated in Queensland. The nickel-PGE-copper mine is characterised mostly by bench scale failures: structurally controlled wedge failures and tight healed structures. Furthermore, some of the $90^{\circ}$ benches, which are close to the only active ramp that permits transit, are full of waste material. In the apatite mine, most of the events can be classified as local bench to sub-bench failures that take place along the major joint planes with limited deformation before failure. Finally, the open cut coal mine, located in the Bowen Basin, has had a series of large highwall failures caused by tectonically disturbed silt/mudstone horizon located above the target coal seam which form large non-uniform blocks that can drop out posing a risk to operations below. A new technological solution of IDS GeoRadar, Hydra-X, which allows for sub-bench monitoring, was deployed to understand the failure mechanisms and to identify instability areas. In the three case studies, the equipment was able to capture sub-millimetre displacements where no visible deformation was visible on the face. These three case studies describe and provide examples of complex modern mining operations where local failures have created the need to revaluate the existing slope monitoring program to have an increasing knowledge of the stability problems and to support geotechnical engineers in managing the risk.
\end{abstract}

Keywords: slope monitoring, sub-bench failures, working areas, geotechnical risk assessment plan, Hydra-X 


\section{Introduction}

Detecting ongoing processes of rock slope deformation that may lead to failure is a critical subject in the field of engineering geology. The mitigation of slope failure risk is of a particular concern in open pit mines, where production works must proceed at a high rate and at the same time safety of workers and integrity of the mining equipment must be guaranteed. Monitoring ground surface displacements is one of the principal preventive measures of open pit mine operations and an assortment of instrumentations could be used for this purpose (Read \& Stacey 2009; Vaziri et al. 2010). Slope monitoring radar, used in the market since 2003, has become one of the go-to technologies and it is a widely used tool for monitoring displacements in open pit mining. Implementing the use of the interferometry technique, it provided the possibility to rapidly measure slope movements with sub-millimetric accuracy over wide areas, reacting quickly to sudden changes of deformation trends by triggering alarms in any weather conditions (Coli et al. 2018). Nowadays, the use of ground-based radar in open pit mines is a standard practice for active slope monitoring (Carlà et al. 2017). Several successful applications of ground-based radar systems to identify large-scale failures in open pit mines have been published in literature. At the same time, the need to manage local-scale instabilities, close to work areas, should be considered. Tactical focus monitoring refers to specific conditions where radars are used to monitor specific areas at risk for the presence of a known instability, or for the proximity of elements at risk, such as areas close to active machineries or mine facilities. In a typical tactical use, the radar is positioned close to the wall that is to be monitored and needs to be frequently relocated because of the proximity of operations or blasting. Set-up should be as quick as possible to provide immediate information on stability conditions if needed (Serangeli et al. 2019). IDS GeoRadar, came up with a new technological solution, Hydra-X, which allows sub-bench monitoring. Thanks to the easy portability, fast set-up and the high resolution provided, the equipment was used in the three case studies described in this paper. They provide examples of complex modern mining operations where local failures have created the need to re-evaluate the existing slope monitoring program to have an increasing knowledge of the stability problems and to support geotechnical engineers in managing the risk.

\section{Interferometric radar technology overview}

All interferometric radars available on the market, for the mining industry, use differences in the phase values of the backscattered electro-magnetic wave to calculate the displacement occurred between two consecutive measurements. In very simple terms, if a reflective target is stable, then the phase registered by the radar will be the same between two consecutive measurements. If a phase change is registered, then a movement of the target has occurred in between the two acquisitions. In 2009 IDS GeoRadar introduced the first interferometric radar based on SAR (Synthetic Aperture Radar) technology in the mining market (Farina et al. 2011). The radar sensor performs multiple acquisitions and for every acquisition receives the signal backscattered by the entire scenario. It performs this task by emitting continuous radio waves with a variable frequency (LFMCW, linear frequency modulated continuous wave radar) and comparing the received echo frequency with the transmitted wave: the difference between the two phases is proportional to the two-way flight time from the apparatus to the target and so to the distance between them. Range resolution, i.e. the ability to distinguish close targets along the line-of-sight of the radar, depends on the transmitted bandwidth while the cross-range resolution, i.e. the ability to distinguish close targets perpendicular to the line-of-sight of the radar, is obtained by means of the SAR technique (Cecchetti et al. 2017). The combination of range and cross-range resolution allows the creation of a bi-dimensional image, where each pixel is a measurement point providing real-time displacement information. The angular resolution was achieved initially exploiting the linear movement of the antennas along a two metres linear scanner now moved to a circular movement along a circumference being the two antennas installed at the edge of a rotating arm, as schematised in Figure 1. The longer is the circumference, the higher the angular resolution (Luo et al. 2014). 

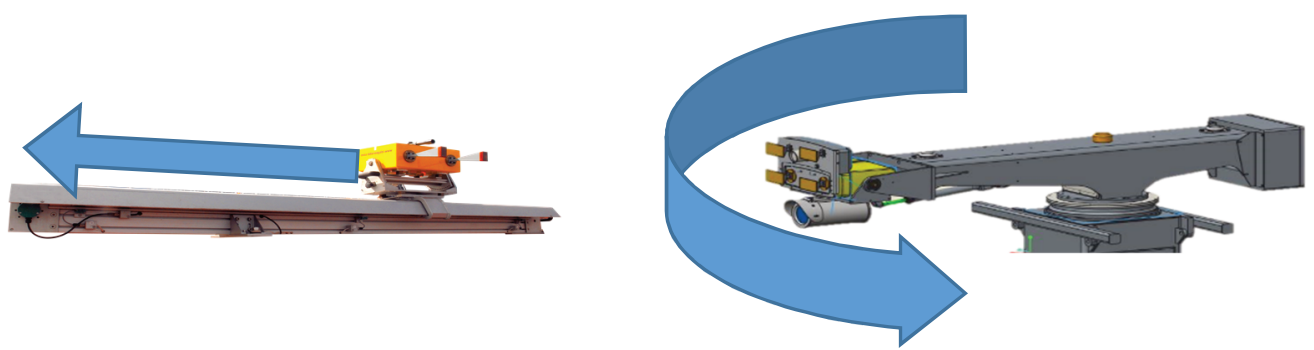

Figure 1 Linear synthetic aperture radar (SAR) versus ArcSAR

Differently from other IDS GeoRadar systems for slope monitoring in open pit mines (IBIS) (Escobar et al. 2013; Farina et al. 2011; Mononen et al. 2016; Ramsden et al. 2015), Hydra-X uses the motion of the radar antenna over a circular trajectory to provide finer angular resolution than conventional beam-scanning radars. Signal processing of the successive recorded radar echoes combines the recordings of multiple antenna positions. This process forms the synthetic antenna aperture and allows the radar to achieve a higher resolution than otherwise possible with a given physical real antenna. The circular trajectory used for obtaining the synthetic aperture (often denoted as ArCSAR) permits a more compact design of the radar and a wider-angle coverage with respect to the traditional linear SAR. It is capable of providing displacement measurement with an accuracy better than $0.1 \mathrm{~mm}$, by combining a very high phase measurement accuracy ( $<0.1$ radians) to a short wavelength $(4 \mathrm{~mm}$ ) (Cecchetti et al. 2017). In the laboratory test, the displacement measure accuracy is about $0.002 \mathrm{~mm}$ (Cecchetti et al. 2018). The system can be divided into two main parts: the acquisition unit, and the power and control unit (Figure 2).

Office

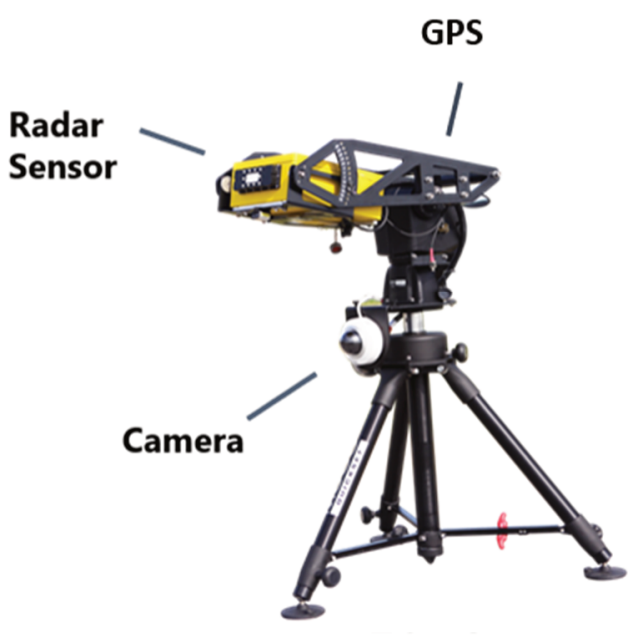

Acquisition unit

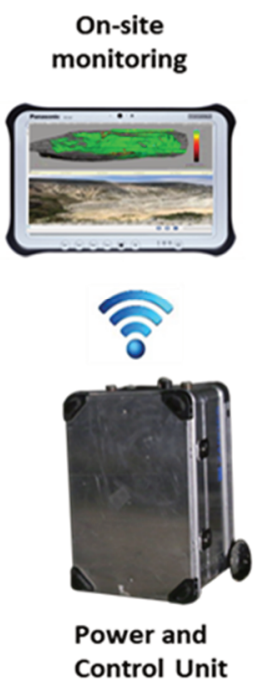

Control Unit

Figure 2 Hydra-X configuration

The acquisition unit consists of a pan/tilt module which rotates the radar sensor in order to perform the SAR acquisition, an optical camera that continuously provides visual feedback of the monitored area and a GPS, for automatic geocoding of radar data. The supply and control unit provides power to the acquisition unit, processes the radar data and provides the network interfaces to remotely control the system. The instrument can perform onsite processing in fact both acquisition software (Controller) and processing software (Guardian) run on an industrial computer integrated inside the supply and control unit. The real-time displacement/velocity heat maps can be visualised onsite on a rugged tablet in wireless connection, or remotely on a desktop PC. The system is designed to be transported by a single person and in transport mode, each box weighs less than $25 \mathrm{~kg}$ and all transport cases are equipped with off-road wheels. It is a remote sensing monitoring system that does not need any reflectors or instruments to be placed on the rock face and its maximum scan range is about $800 \mathrm{~m}$ from the point of installation. 


\section{Data}

Hydra-X is a system specifically designed to address the challenges of focused monitoring in open pits, strip coal mines, tailing dams and industrial minerals operations. In this paper three case studies are described reporting three different examples on how focused monitoring was useful to mitigate the risk of sub-benches failures, manage specific working areas and take care about critic areas inside the mine.

\subsection{Bowen Basin case study}

The case study in this section is based in a large-scale Bowen Basin open cut coal mine in Queensland, Australia. The annual output is $12 \mathrm{Mtpa}$ of thermal and hard coking coal the mine has been in operation since 2008. It utilises a $100 \%$ truck shovel mining method with historically sporadic use of slope stability radars. Adverse structural conditions resulting from complex regional tectonics have led to an increase in large-scale wedge failures. With the life-of-mine expected to stretch into the 2030s including possible underground operations, the potential for large-scale geotechnical failures which will require operational management are expected to continue. The total operation has an active highwall strike length of $7.500 \mathrm{~m}$ with a total depth of $120 \mathrm{~m}$. The maximum bench height is $60 \mathrm{~m}$ with berms ranging from $25-40 \mathrm{~m}$ depending on the operational requirements. Highwall angles of $65-70^{\circ}$ make up the majority of highwalls with $45^{\circ}$ softwalls being used in areas with unfavourable fault and joint orientations.

The Bowen Basin contains the largest coal reserves in Australia and is one of the largest deposits of bituminous coal in the world. The Bowen Basin is approximately $650 \mathrm{~km}$ long and $200 \mathrm{~km}$ wide and varies in depth to over 1,000 m. Due to the size of the deposit, most coal mines within the Bowen Basin target specific deposits. The mine shown in this case study targets the Rewan Group sedimentary system with the target coal seam being part of the Rangal Coal measures. These measures are late Permian in age at approximately $250 \mathrm{Ma}$. Coal from these deposits consists of hard coking, thermal and low volatile $\mathrm{PCl}$ coals. Interburden between the coal measures consists of interbedded coarse to fine grained sandstone, siltstone and carbonaceous shale. Major structural features of the region include the Isaac fault running through the east of the deposit plus minor associated thrust systems within the active mining area (Figure 3 ).

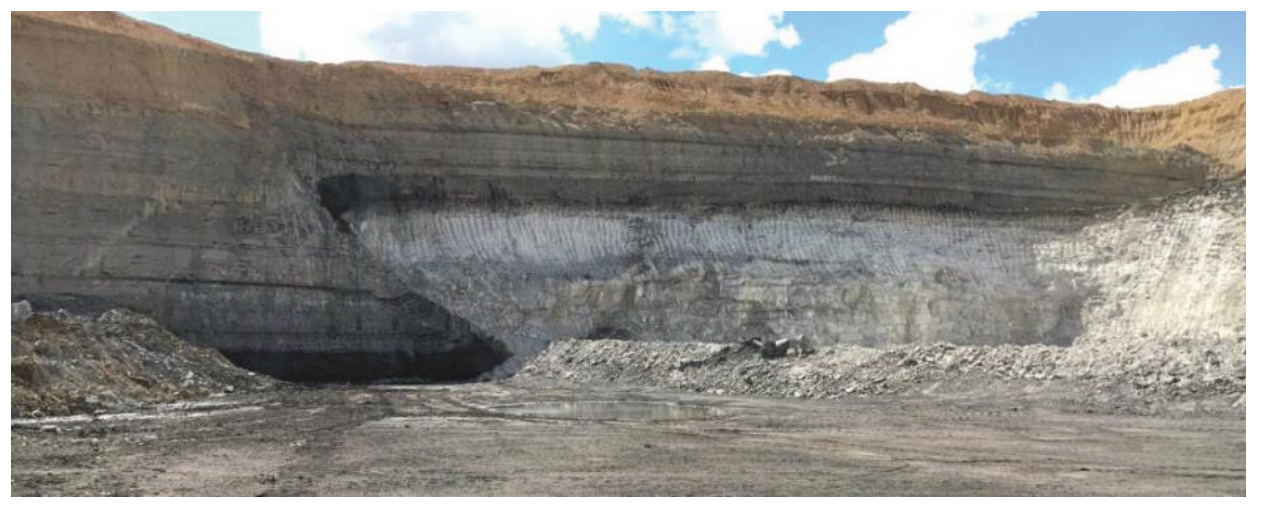

Figure 3 Typical faulting and stratigraphic sequence found in Bowen Basin open cut coal mine

Due to the redistribution of the tectonic stresses within the deposit formation, associated listric structures have formed around the large-scale faulting. These structures are located mainly in the weaker carbonaceous mud/siltstone horizon underlying the competent sandstone unit. The rock mass shows a variation in intact rock strength ranging from 27-33 MPa, with the carbonaceous unit having a lower Geological Strength Index (GSI) value of 30 allowing for significantly weaker material than the more competent overlying sandstone unit with a GSI of 60-70. The relatively high intact rock strengths further highlight the failure mechanisms being observed across the mine site as being structurally driven, primarily from the carbonaceous shale horizon. The weak horizon appears to be approximately 5 to $10 \mathrm{~m}$ in thickness and lies directly above the basal coal seam within the mining lease. Once mining progressed through the thrust system, the listric surfaces became an issue to highwall stability and a risk to personnel and equipment working below. Due to 
the uncertainty and variability in the orientation and location of these structure, their occurrence is generally not identified until the wall is exposed (Figure 4).

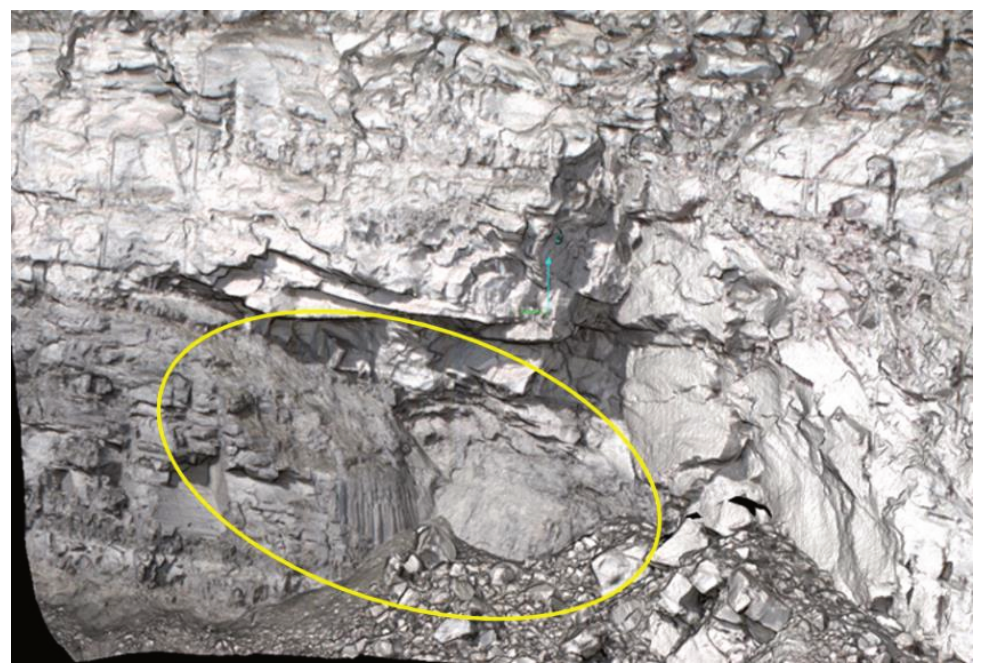

Figure $4 \quad$ Listric structures circled in yellow

Following a series of large-scale highwall instabilities due to the listric structures sliding out and then undercutting the competent sandstone unit above, a targeted monitoring trial with Hydra- $X$ was implemented. The system configuration used for the trial was a compact trailer mounted unit running off a combination of solar and batteries, designed to be deployed and packed-up quickly throughout the trail. This equipment was selected directly for its resolution (@100 m, $0.15 \times 0.80 \mathrm{~m}$ ). A section of exposed highwall was selected where a wedge failure had occurred. The failure happened on 13 January 2019 where a $3.000 \mathrm{bcm}$ large sandstone wedge had fallen out of the wall, see Figure 5. It was assumed that the same failure mechanism had occurred where the underlying siltstone had failed post coaling, undercutting the competent sandstone unit. A continuous joint set was seen running through the sandstone unit providing one release plane for the wedge with the second plane either being a secondary joint set or breaking under tension.

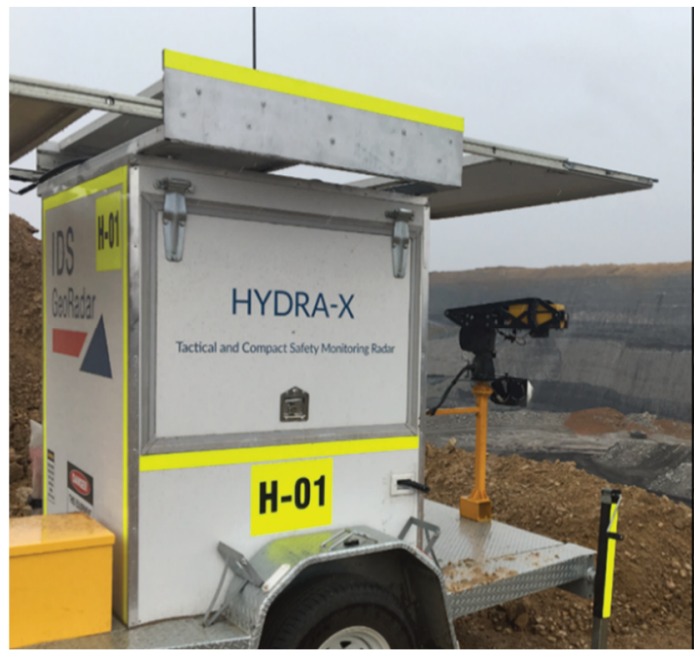

(a)

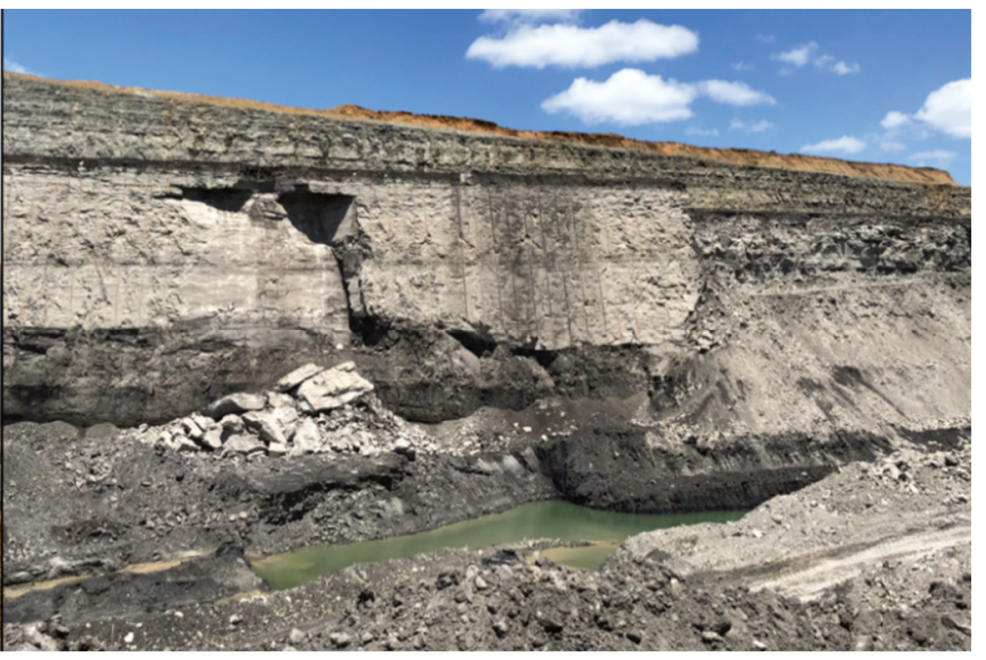

(b)

Figure 5 (a) Trailer Hydra-X; (b) Initial highwall failure occurred in the south side of the mine on 13 January 2019

On 15 January 2019, the radar was deployed to monitor the collapsed area and it was located approximately $280 \mathrm{~m}$ from the failure and scanned a total distance of $700 \mathrm{~m}$ of the highwall. The area being monitored was 20 times bigger than the original collapse as the geotechnical engineer wanted to observe if in the closed 
work area, further displacement could be detected. Throughout no visible deformation or further deterioration was witnessed on the highwall through daily inspections, reviewing the data captured by the unit, clear deformation within the siltstone unit was seen with an average movement of $16 \mathrm{~mm}$ across the 14 days of monitoring, see Figure 6.
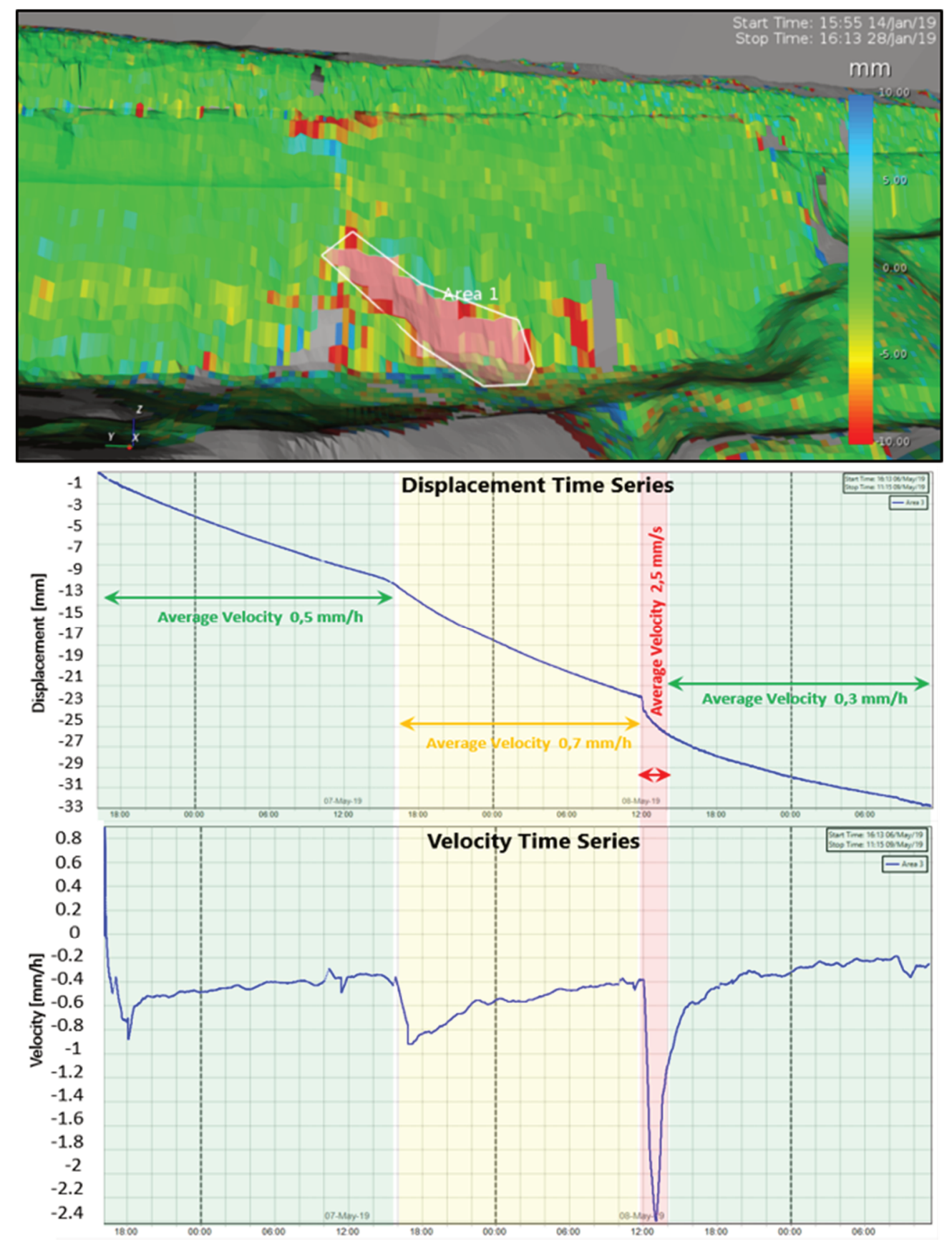

Figure 6 Moving area in the displacement map (orientation of view southwest), and displacement and velocity time series of the area

Deformation plots of each area confirm what we thought was occurring with the highwall, that is, relaxation and movement within the lower siltstone unit. This movement occurs gradually once the highwall face is exposed and eventually leads to failure and undercutting of the competent sandstone unit above. Movement was also detected within the siltstone band North of the active failure area, as small discrete blocks/listric surfaces dropped out as the wall further deteriorated (see Figures 7 and 8). 


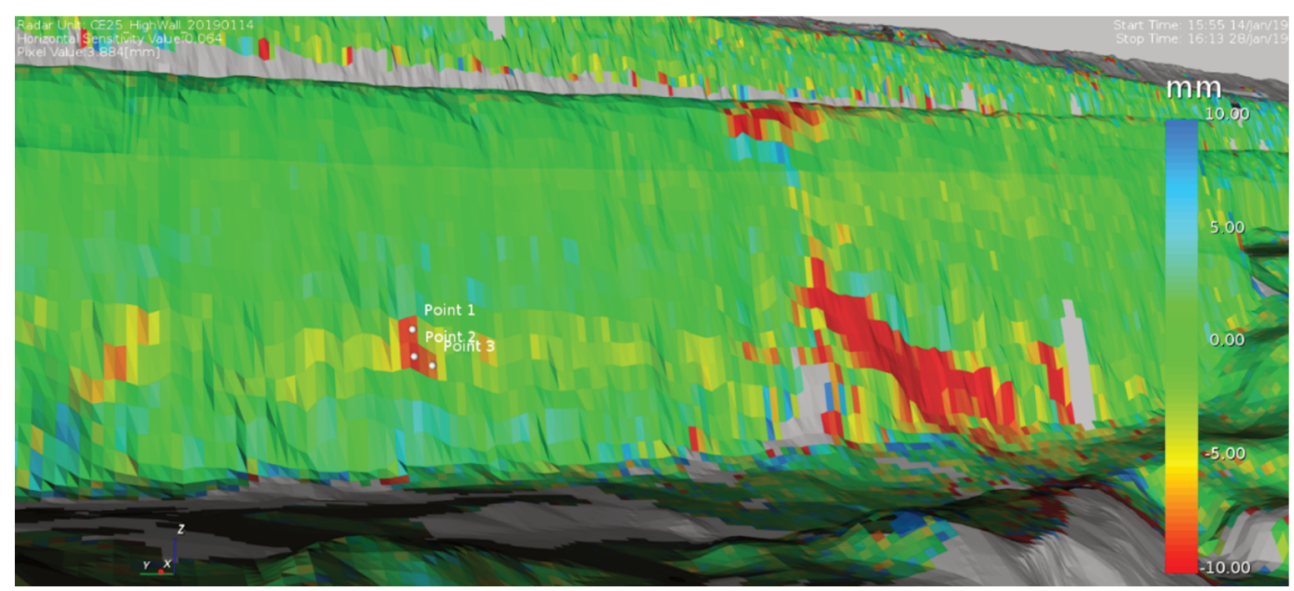

Figure 7 Additional movement in the carbonaceous mud band north of the main monitoring area and displacement average result for points selected on deteriorating siltstone band

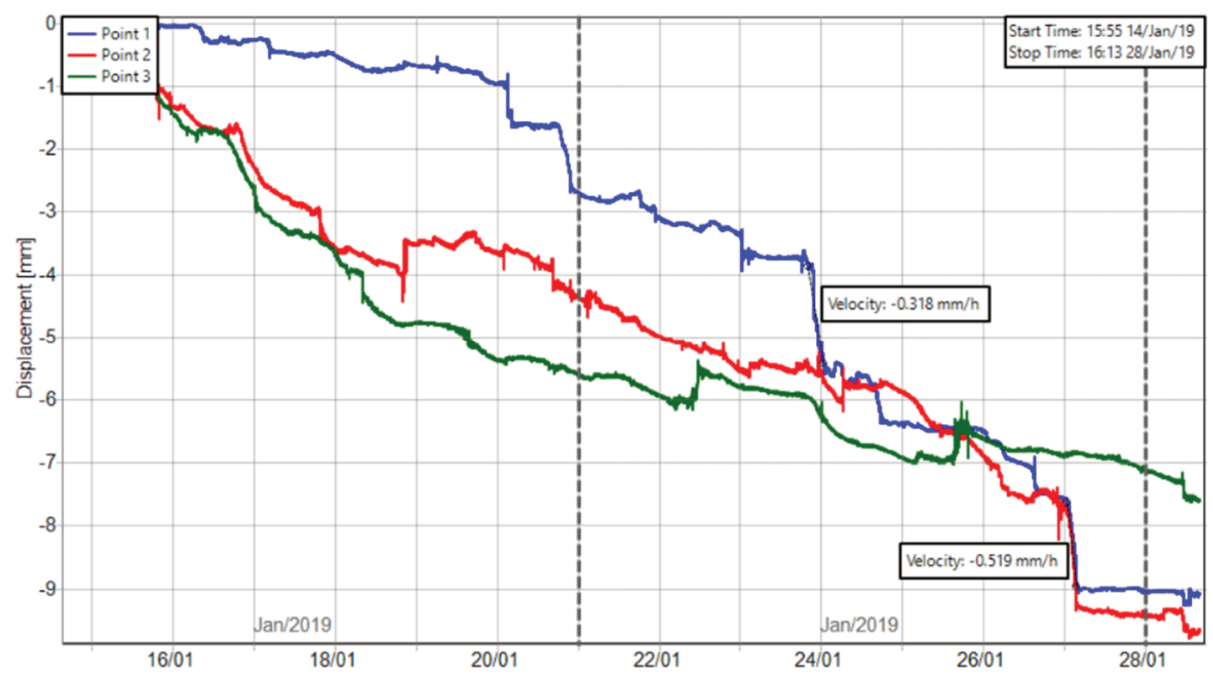

Figure 8 Displacement time series of the three points

This confirmed to site that the failure mechanism for its recent highwall issues initiates in the siltstone and that sub-millimetre movement is detected prior to failure within the sandstone unit. Just after the trial was completed, complete bench failure of the highwall occurred as seen in Figure 9. Where the underlying siltstone failed, undercutting the sandstone unit and due to the continuous discontinuity, caused a large wedge (approximately $30 \mathrm{~m}$ in height and $7.500 \mathrm{bcms}$ ) to drop out.

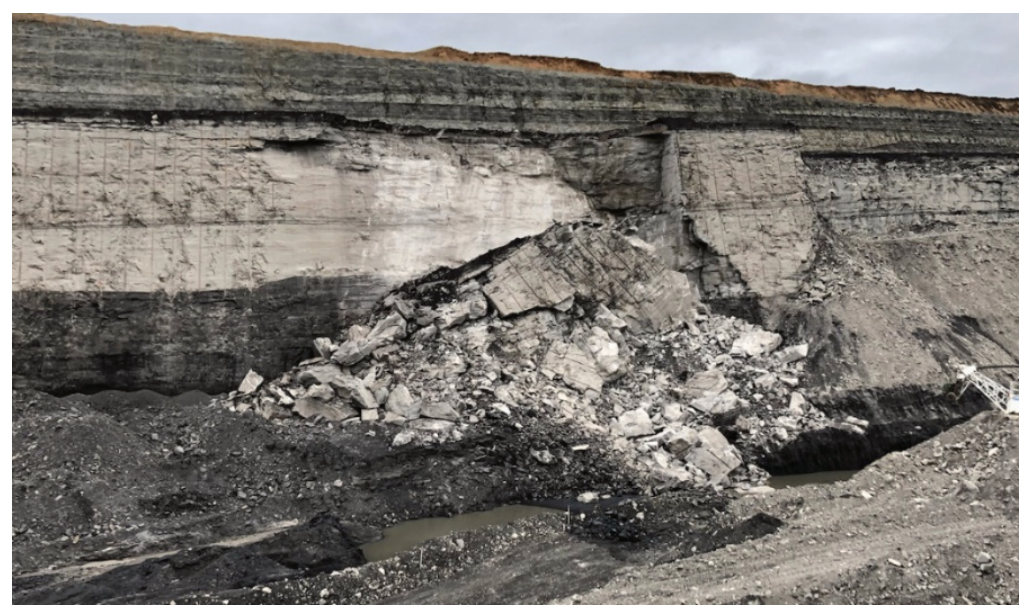

Figure 9 Post-failure of the highwall after the trial was completed 


\subsection{Yara case study}

Yara Suomi Oy operates two open pits in the Siilinjärvi area in Eastern Finland, the mine life is foreseen to stretch up to 2035 and it is currently the only apatite mine in production in Europa. The main pit, called Särkijärvi, is 3,000 m long, $900 \mathrm{~m}$ wide and $250 \mathrm{~m}$ deep, while the satellite pit, Saarinen, is $800 \mathrm{~m}$ long, $400 \mathrm{~m}$ wide, $100 \mathrm{~m}$ deep and the height of the benches is between 28 and $30 \mathrm{~m}$. The two pits belong to the same elongated orebody, it is 2.6 billion years old, which dimensions are $14.5 \mathrm{~km}$ long, 1,000 m wide and with a known depth of $800 \mathrm{~m}$. While the surrounding rocks consist of granite, gneiss and diorite, the rocks of the complex are fenite, diabase and carbonatic rock. Fenite is an altered rim around the orebody, diabase occurs as crosscutting dykes and carbonatic rocks host the apatite ore. Most of the failures occur during spring and autumn when freezing and thawing cycles are at their strongest. If during winter season long continuous periods of freezing temperatures are reached, there are usually no instabilities. Blasting vibration, the high precipitation, the freezing/thawing cycles, a shear zone which runs parallel to the pit wall and the presence of fenite xenoliths inside the orebody, are the main contributing factors of failures. The largest failures are due to long, steeply dipping, continuous shear zones and the main failure mechanism is toppling. In some cases, shear zones are so heavily fractured that rotational failures might also occur. The different kinematics are also linked to the type of rock: fenite, diabase and diorite (waste rocks). These are more brittle and tend to cause wedge and plane failures. Diabase and diorite veins have often three sets of joints that create wedges of different sizes $\left(1-1,000 \mathrm{~m}^{3}\right)$. The carbonatic rocks on the other hand, are more plastic, and generate more toppling failures. The Särkijärvi pit has been active since 1979 and, even though it has been working for over 30 years, in 2007 the production rates increased significantly, and rock mechanics and mine safety started to become a concern. Yara's mine staff decided to purchase four radar systems to start critical safety monitoring of the pit walls. In December 2018 the mine had a bench scale failure on the northeast part of Särkijärvi. The size of the block was $15 \mathrm{~m}$ tall $\times 11 \mathrm{~m}$ wide $\times 10 \mathrm{~m}$ thick and it was left on the wall with tension fractures clearly visible. This was obviously seen as a risk that had to be removed and for this reason the equipment was implemented in spring 2019 to monitor the area (see Figure 10). The Hydra-X was powered with a diesel generator and the touchpad controlling the radar was granted remote access with a $3 \mathrm{G}$ router and a SIM card.

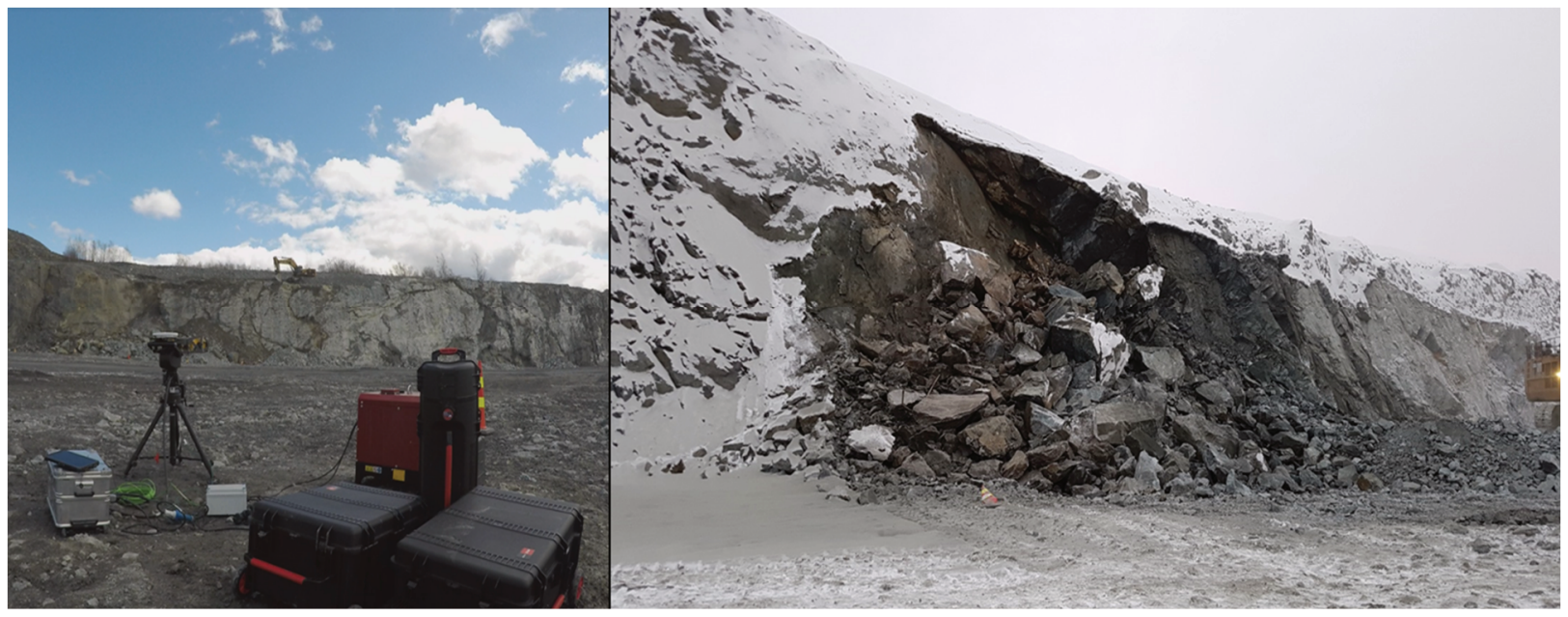

(a)

(b)

Figure 10 (a) Hydra-X installation in spring 2019; and (b) Initial plane failure that occurred in December 2018

The unit was located approximately $100 \mathrm{~m}$ from the $20 \mathrm{~m}$ bench, monitoring an area of around 2,580 $\mathrm{m}^{2}$. The installation was set up in the spring because the mine staff decided to wait until all snow had melted in order to see and map the structures clearly. It was decided to use it to monitor the loose rock block that was left unstable after bench scale slope failure happened next to it. Monitoring was carried out because a dozer was excavating the overburden on top of the unstable block. The continuous monitoring undertaken on the 
area gave the crew the possibility to understand that there were no displacements on the pit wall while the loose debris piles were in constant movement. A period of three days was defined to show the behaviour of the working area (Figure 11).

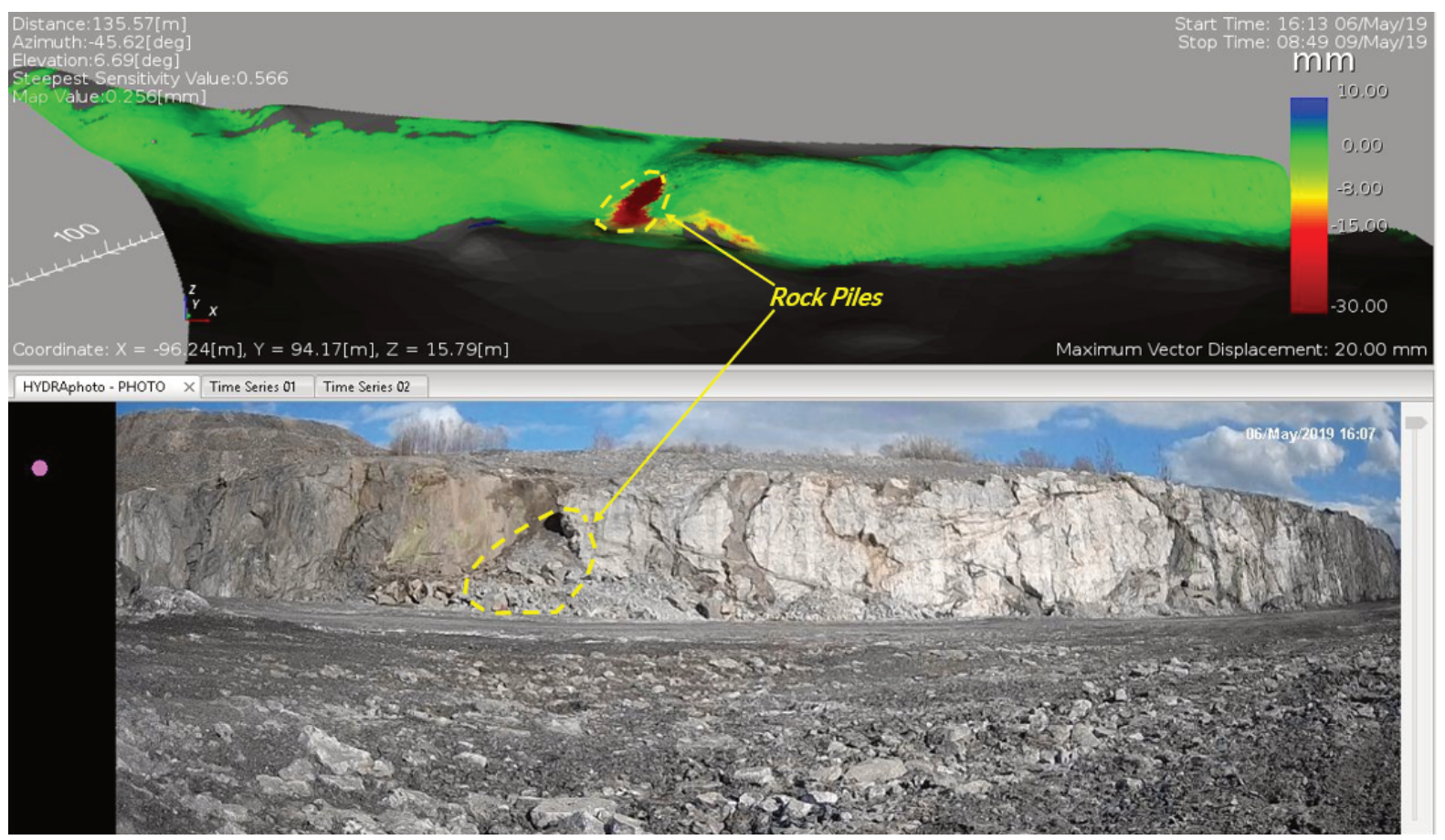

Figure 11 Hydra-X data showed displacement in loose rock piles

To define the constant movement inside the loose debris piles, six points have been analysed (points 1, 2, 3, 4, 5 and 6), which location and time series are shown in Figure 12.

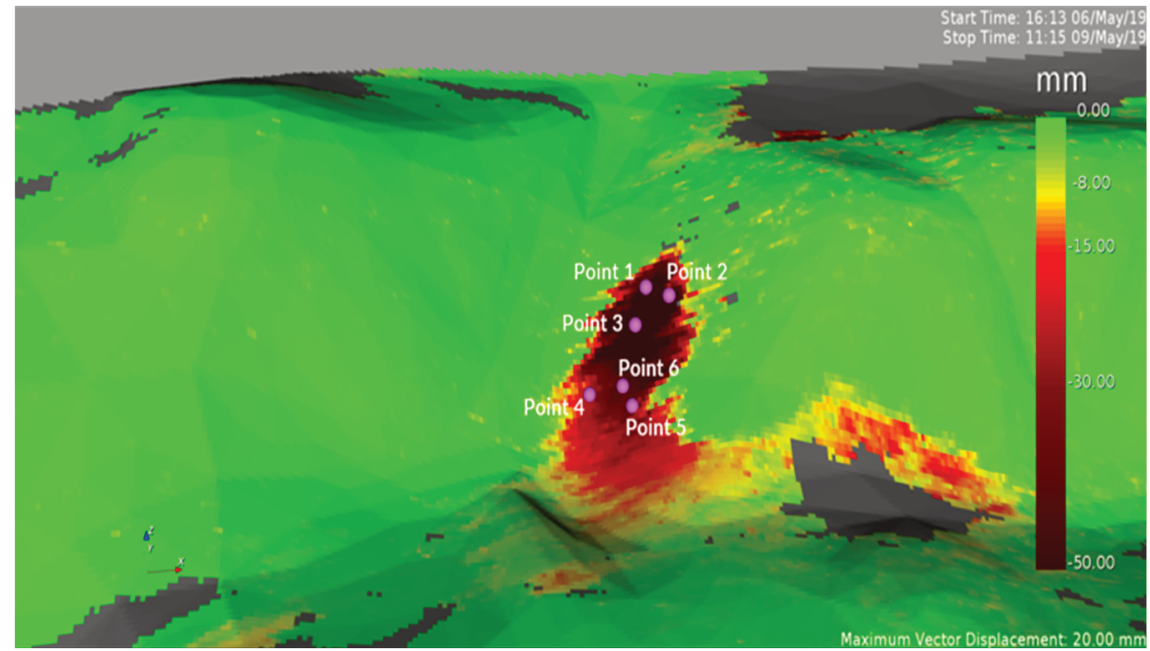

Figure 12 Location of the points analysed

Points located in the upper part of the moving area (points 1,2 and 3) show a cumulative displacement around $60 \mathrm{~mm}$, while points located at the bottom (4, 5 and 6) register a value between 40 and $25 \mathrm{~mm}$ in three days. An acceleration event is visible on 8 May around $12 \mathrm{pm}$ and the displacement time series of the entire moving area has been analysed in order to obtain the general deformation trend of the rock piles (Figure 13) that encompassed by an area of $45 \mathrm{~m}^{2}$. 


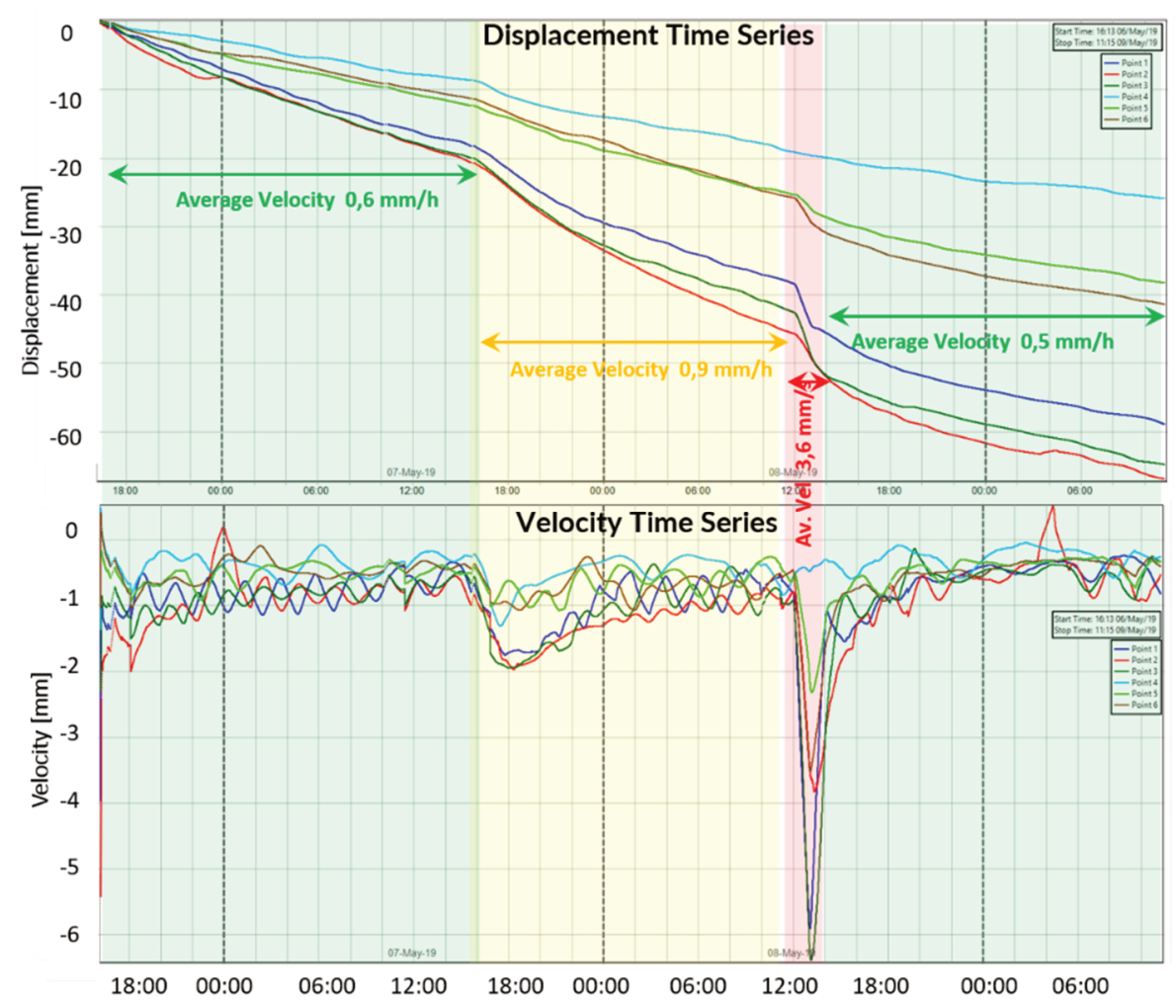

Figure 13 Displacement and velocity time series of points 1, 2, 3, 4, 5 and 6

\subsection{Kevitsa case study}

Kevitsa, a mine of New Boliden, is located in the north of Finland, in Lapland, closed to Sodankylä. The deposit was discovered in 1987 while the production started in 2012. It is composed by a round pit producing nickel-PGE, copper and gold where the diameter is about $1,000 \mathrm{~m}$ and $220 \mathrm{~m}$ deep (Figure 14).

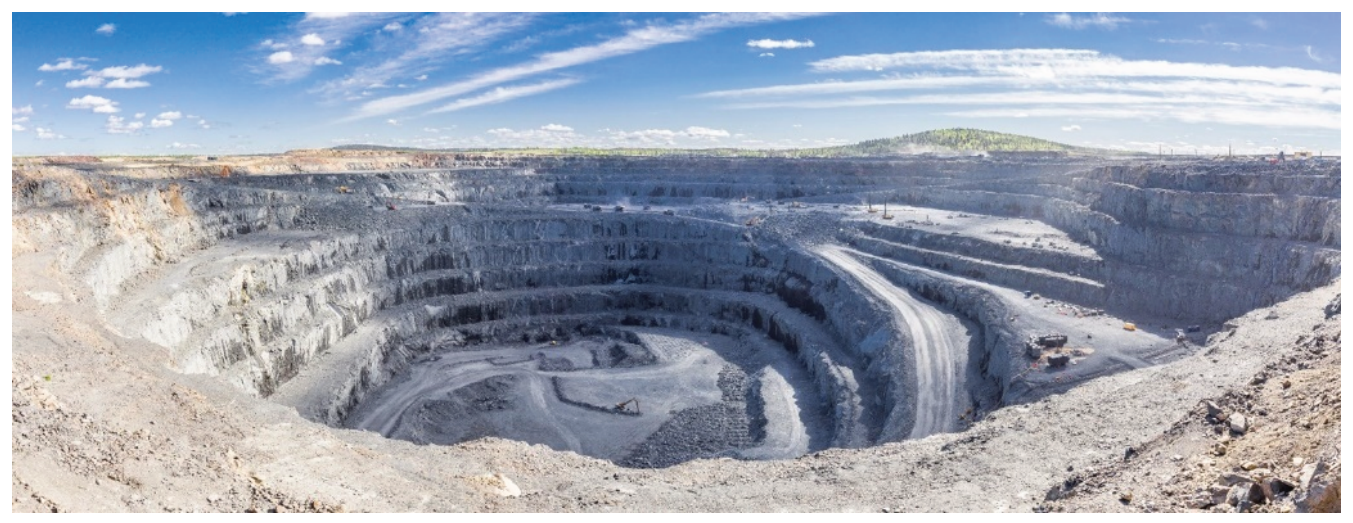

\section{Figure 14 Overview Kevitsa mine}

The mineralisation belongs to Kevitsa intrusion situated within the northeastern Fennoscandian shield, and compromises olivine websterite in the northeast, gabbro in the southwest, and dunite outcropping in the central part. The mine is situated fully within the olivine websterite unit.

The mine has multiple active mining production areas (at the upper part and in the bottom of the pit) and currently it is operating in the stage 3 cut back. The mine will expand in with to the south and also in depth. The pit is almost circular and has only one main active haulage ramp to reach the bottom of the pit floor with high traffic of different mining equipment. The homogeneity of the rock mass allows using similar design parameters: $24 \mathrm{~m}$ height benches at angles from $70^{\circ}$ to $90^{\circ}$. Most of the benches are vertical. Most of the failures occur during spring and autumn while in winter time, during long time of freezing temperature, the 
number of instabilities are reduced. The rock mass quality of the entire deposit is quite high (unconfined compressive strength up to $300 \mathrm{MPa}$ ) and the fracture zones are limited to specific areas. Fifteen major structures were identified, making it necessary to constantly update the pit design to prevent instabilities. The consistent geology features make it irrelevant in regard to source of instabilities, and historically these were not driven by major structures. Most of the failures are bench scale structurally controlled wedges with a size around $10 \times 10 \times 10 \mathrm{~m}$ and several hundreds of tons in weight, moving over undulating tight structures. Falls of loose materials lying on the benches typically occur on the east/south walls. These loose materials come from production activities on stage 2 and have filled the lower berms, allowing new loose blocks to fall all the way down to the main access ramp.

If initially in 2012 the pit was quite small, between 2012 and 2017 the dimension of the pit increased significantly, and the rock mechanics started to have a more important role than early days. In 2017 Kevitsa's mine staff decided to purchase one radar system, an IBIS-Rover, to start critical safety monitoring of almost all the pit walls. Between 2018 and 2019 Kevitsa started to feel the need to have a safety critical and tactical tool, quickly deployable, with high resolution to monitor specific working area inside the mine and also to complete the monitoring of the entire pit (with the IBIS-Rover the field of view is about $270^{\circ}$ ).

In November 2018 Kevitsa decided to monitor a specific area of the mine, the east wall, with an instrument that could measure, identify and alarm if a little displacement may happen. A remote excavator was working on a specific wider bench, named +90 bench, because all the safety benches were full of blasted material from the upper stage 3 cut back. The aim was to create wider catchment bench, about $25 \mathrm{~m}$. Furthermore, the safe benches where the excavator was working were above the main and only ramp to stage 2 cut back, where only single line truck access was implemented due to rockfall risk. This ramp was actively used from the operation to arrive to the other active area at the bottom of the pit. The excavator was controlled from a control cabin inside a container localised at $100 \mathrm{~m}$ from it. The mine staff decided to install the Hydra- $X$ close to the container to have the complete overview of the area and to monitor the sector above the excavator. The cameras positioned on the excavator were useful for operation and positioning, but not good enough to monitor above the excavator. Figure 15 shows the main ramp, the excavator on the +90 working bench, the remote controlled excavator and the radar data.
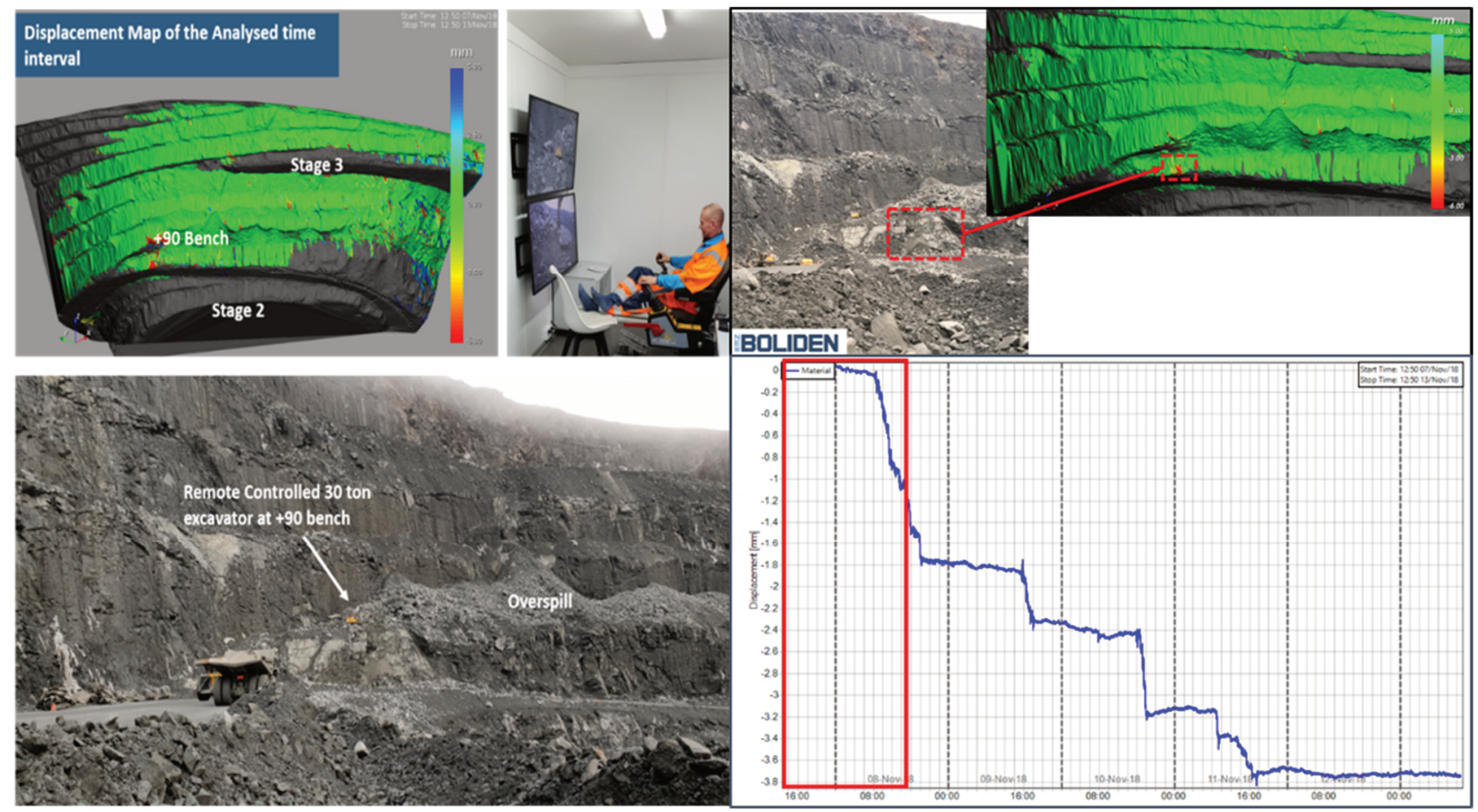

Figure 15 Displacement map; monitored area; excavator control room and displacement time series. The area within the red rectangle is analysed in detail in the following section 
The equipment was located approximately $250 \mathrm{~m}$ from the $24 \mathrm{~m}$ bench, monitoring an area of around $4,500 \mathrm{~m}^{2}$. The installation was set up in the autumn because the mine staff wanted to clean the +90 bench before winter. It was decided to use Hydra-X to monitor the benches above and also the loose rock block that may fell during the cleaning work of the excavator, down to the main ramp. A detailed analysis has been performed on the first day of data. The displacement time series shows $2 \mathrm{~mm}$ of cumulative displacement (Figure 16).

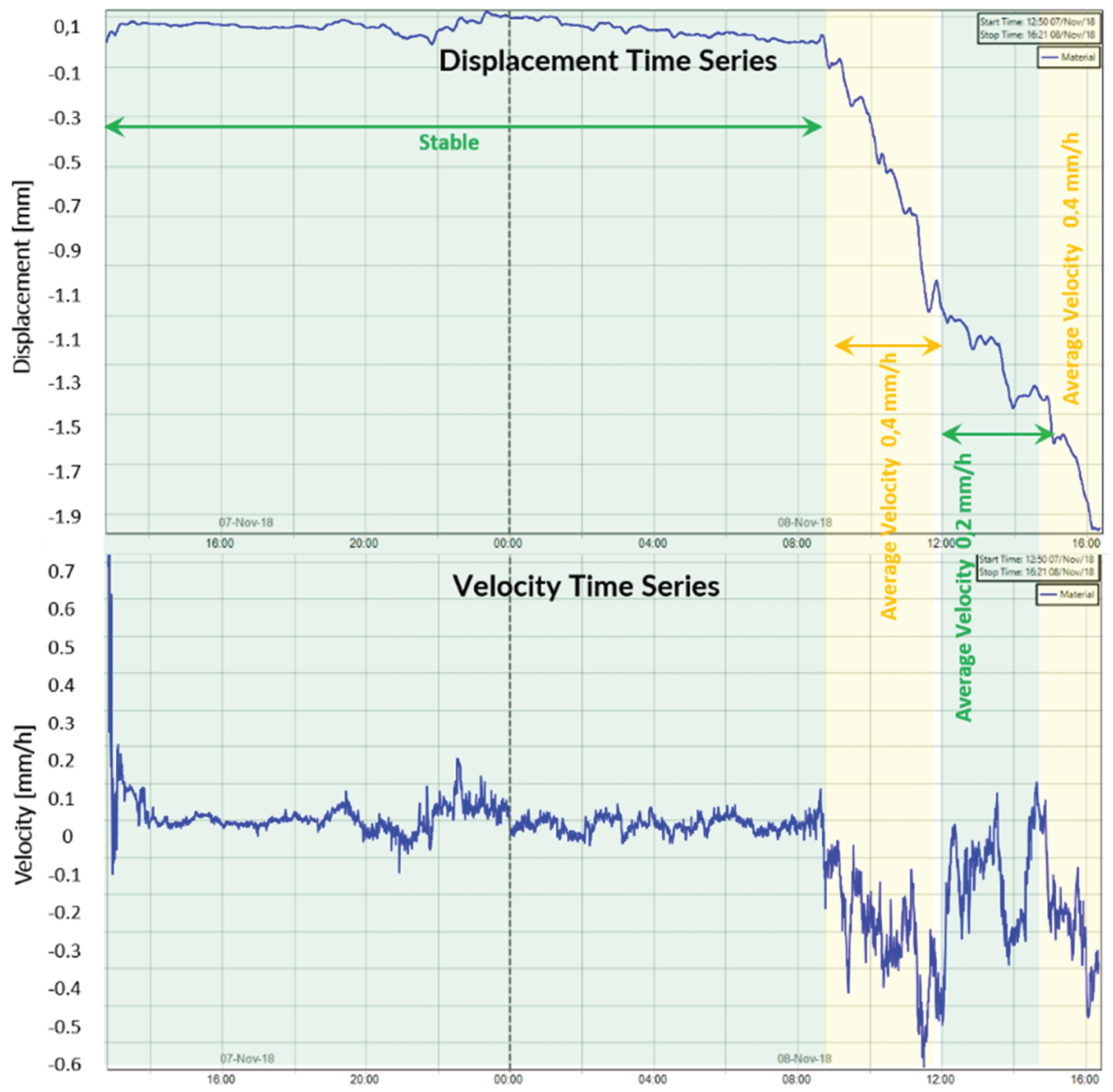

Figure 16 Displacement and velocity time series

A detailed analysis has been performed on the first day of data. The displacement time series shows $2 \mathrm{~mm}$ of cumulative displacement. The time series has been divided in different sector according to the deformation rate measured by the radar. Green sectors show a lower velocity average value compared to the yellow sector. The overall cumulative displacement considering six days of data is around $3.8 \mathrm{~mm}$, due to the mobilisation of material by the excavator. Hydra- $X$ was able to monitor continuously the area above the excavator with a focus on the loose material on the east wall benches, guaranteeing the possibility for trucks and other machineries to use the main ramp in a safe and controlled environment. In the six days showed in this analysis, it was possible to notice a displacement of $3.8 \mathrm{~mm}$ due to the mobilisation of material by the excavator. Hydra-X was able to monitor continuously the area above the excavator and mainly, the loose material on the east wall benches guaranteeing the possibility for trucks and other machinery to use the main ramp in a safe and controlled environment.

\section{$4 \quad$ Results}

The three case studies described in this paper report different examples on how focused monitoring was useful to mitigate the sub-benches failure risk and manage specific working areas (as the example of Yara), to take care about critic element inside the mine (the case study of Kevitsa) and to predict failures (Bowen 
Basin coal mine). In the case study of Yara, thanks to the continuous monitoring of the area below the bench, the clearing of the debris could be carried out safely. The dozer could work in a safe way knowing that the material was stable, and the data processing onsite with alarms allowed the operator to get alarms in case of movement. The continuous monitoring undertaken in Kevitsa gave to the geotech the tranquillity to know that operators onsite could be alarmed in case of any displacements due to loose rocks laid on the berms or unstable areas of the benches above the main ramp, where trucks were passing on the main line, or the remote excavator, working on the +90 bench.

Finally, as a result of the trial in the Bowen Basin and thanks to the information gathered by the equipment, site was able to confirm the correct failure mechanism that was occurring on the highwalls after crossing the large thrust system. It was clear that the underlying siltstone unit begins to relax/dilate as it is exposed in the face allowing the listric surfaces to mobilise. Due to the random nature of the listric surfaces, site has now implemented design changes to minimise the impact on the highwall. They include reducing the wall angle from $70^{\circ}$ to $65^{\circ}$ and the incorporation of a catch bench into the wall design to reduce the height of the sandstone unit sitting above the weak siltstone unit below.

\section{Conclusion}

The mitigation of slope failure risk is an essential part of the safety strategies in open pit mines. Special attention has been given to local-scale instabilities within active mining areas which can be difficult to manage. Sub-bench scale failures pose a threat to miners and machinery due to the closeness to working areas and identifying these areas before failure helps minimise production interruption. Slope monitoring radar, used in the market since 2003 , had become one of the go-to technologies and it is a widely used tool for monitoring displacements in open pit mining. HYDRA-X, the equipment used to conduct these case studies, is an interferometric radar system specifically designed to address the challenges of focus monitoring in open pits, strip coal mines, tailings dams and industrial minerals operations. The three case studies described in this paper report different examples on how focus monitoring was useful to mitigate the subbenches failure risk and manage specific working areas (as the example of Yara), to take care about critic element inside the mine (the case study of Kevitsa) and to predict failures (Bowen Basin coal mine).

\section{References}

Baczynski, NRP \& Bar, N 2017, 'Landslide monitoring and management challenge in remote Papua New Guinea in Mikos', Advancing Culture of Living with Landslides: Proceedings of the 4th World Landslide Forum, Springer, Cham, pp. 343-354.

Carlà, T, Farina, P, Intrieri, E, Botsialas, K \& Casagli, N 2017, 'On the monitoring and early-warning of brittle slope failures in hard rock masses: Examples from an open-pit mine Engineering geology', Engineering Geology, vol. 228, pp. 71-81.

Cecchetti, M, Rossi, M, Coppi, F, Bicci, A, Coli, N, Boldrini, N \& Preston, C 2017, 'A novel radar-based system for underground mine wall stability monitoring', Proceedings of the First International Conference on Underground Mining Technology, Australian Centre for Geomechanics, Perth, pp. 431-444.

Cecchetti, M, Rossi, M \& Coppi, F 2018, 'Performance evaluation of a new MMW Arc SAR system for underground deformation monitoring', Proceedings of Active and Passive Microwave Remote Sensing for Environmental Monitoring, The International Society for Optics and Photonics, Bellingham, https://doi.org/10.1117/12.2323828

Coli, N, Leoni, L, Coppi, F \& Preston, C 2018, 'Evolution of synthetic aperture radar safety critical monitoring in open pit mines', Proceedings of the 2018 International Symposium on Slope Stability in Open Pit Mining and Civil Engineering, BCO Congresos, Barcelona.

Escobar, A, Farina, P, Leoni, L, lasio, C \& Coli, N 2013, 'Innovative use of slope monitoring radar as a support to geotechnical modelling of slopes in open pit mines', in PM Dight (ed.), Proceedings of the 2013 International Symposium on Slope Stability in Open Pit Mining and Civil Engineering, Australian Centre for Geomechanics, Perth, pp. 793-802.

Farina, P, Leoni, L, Babboni, F, Coppi, F, Mayer, L \& Ricci, P 2011, 'IBIS-M, innovative radar for monitoring slopes in open-pit mines', Proceedings of the 2011 International Symposium on Rock Slope Stability in Open Pit Mining and Civil Engineering, Canadian Rock Mechanics Association.

Luo, Y, Song, H, Wang, R, Deng, Y-K, Zhao, F \& Xu, Z 2014, 'Arc FMCW SAR and application in ground monitoring', IEEE Transactions on Geoscience and Remote Sensing, vol. 52, pp. 5989-5998.

Mononen, S, Suikkanen, M, Coli, N, Funaioli, G \& Meloni, F 2016, 'Critical real time radar monitoring of sub-bench failures at Yara Suomi Oy Siilinjärvi Open Pit Mine (Finland)', in R Ulusay, Ö Aydan, H Gerçek, AM Hindistan \& E Tuncay (eds), Proceedings of EUROCK 2016: Rock Mechanics and Rock Engineering: From the Past to the Future, Taylor \& Francis Group, London. 
Ramsden, F, Coli, N, Benedetti, Al, Falomi, A, Leoni, L \& Michelini, A 2015, 'Effective use of slope monitoring radar to predict a slope failure at Jwaneng Mine, Botswana', Proceedings of the 2015 International Symposium on Slope Stability in Open Pit Mining and Civil Engineering, The Southern African Institute of Mining and Metallurgy, Johannesburg.

Read, J \& Stacey, P 2009, Guidelines for Open Pit Slope Design, CSIRO Publishing, Clayton.

Serangeli, A, Merlo, A, Boldrini, N \& Santora, D 2019, 'The application of synthetic aperture radar in open pit mining', Proceedings of the 26th Conference of the Society of Mining Surveyors and Geologists.

Vaziri, A, Moore, L \& Ali, H 2010, 'Monitoring systems for warning impending failures in slopes and open pit mines', Natural Hazards, vol. 55, no. 2, pp. 501-512. 